\title{
Student Satisfaction with Using Independent Study Logs as Part of English Classes
}

\author{
Mary Frances Litzler \\ Department of Modern Philology, University of Alcala, Alcala de Henares, Spain
}

\begin{abstract}
Journals and diaries have been used in many different kinds of courses in a variety of disciplines so that students can reflect on their learning experience and make it more personal. This paper involves a modified version of diaries in which students briefly record the work they have done using English as a foreign language or coming into contact with the language along with their reactions to the experience, so that the teacher can give them individual feedback with a view towards helping them to become more autonomous in their learning. It describes the results of a questionnaire given to students upon completion of their English courses to determine their impressions about doing study logs in two different class settings, both at the university level. The results for one of the groups reveal that the learners were highly satisfied with the experience, while the other group had mixed reactions. The nature of the two groups and the procedure followed in the two cases suggest that varying approaches to different kinds of groups might improve the experience for the students involved.
\end{abstract}

Index Terms - diary studies, learner autonomy, EFL, tertiary studies, motivation, learning strategies, feedback

\section{INTRODUCTION}

Journals and diaries have been used in a variety of disciplines for several decades. They are often used as a place for students to write up what they have learned from assigned readings along with their own reflections on the content in an effort to have learners process more deeply the course contents by integrating them into their personal experience. In the foreign language classroom they are used so that students can comment on their learning process and any difficulties encountered in acquiring the new language. This study involves a version of diaries in which students briefly record in a $\log$ what they have done to use and/or practice English outside their English classes along with reactions, as opposed to writing up longer reflections. The instructor or professor can then provide feedback to help them to become more efficient and autonomous in their independent study time. In this sense, the logs are not used to provide students with a way of integrating the course contents into their personal experience, but rather they are used to encourage them to make the use and practice of English as a foreign language a more frequent part of their daily lives and to provide a vehicle for individualized dialogue between the student and the professor.

Two groups who used logs as part of their English courses were given a short questionnaire to complete with their opinions about doing logs at the end of the semester. The main objective of the questions was to determine whether the students felt that doing the logs had been worthwhile and whether the activity should be modified in future courses and how to adjust it. This study provides some background information on diaries and students' responses to them as reported in the literature, a description of the groups that used logs in their English classes for this particular study, and their reactions to the activity as revealed through their responses to the questionnaire.

\section{LITERATURE REVIEW}

\section{A. Diary Studies}

Diaries and journals have been used in a variety of disciplines of study for several decades now. In writing them as part of a university course students are typically asked to record information on what they have learned in class or through readings along with additional information, such as their personal reactions to the material (Pavlovich, Collins \& Jones, 2007), applications of the theoretical concepts to events around them (Connor-Greene, 2000), or reflections on their learning process and changes in their thinking and learning (Blaschke \& Brindley, 2010). In the context of foreign language learning, Bailey \& Ochsner (1983) recommend that diarists regularly write down descriptions of their experiences learning the language including "events, details, and feelings" (p. 189). Diaries and journals used in foreign language courses at the university level tend to follow this example but add their own focus. For example, Halbach (2000) had students record activities they had done to practice English, problems they had encountered, and the solutions they proposed to remedy the situation in the future (p. 86). Huang (2005) had students write a journal with their understanding of the foreign language reading process and any other ideas on learning the different aspects of English such as listening, speaking, writing, grammar and vocabulary (p. 611).

There are a number of benefits to using diaries in the classroom. According to Moon (2010), diaries and journals are "helpful in personalizing and deepening the quality of learning" (p. 3). For second language learning, Nunan (1992) 
lists seven advantages of diary research in teacher education programs, several of which can be extended to the language classroom and learning situation. These particular ones are the possibility for students to mention problems they are having with the course, increased autonomy in learning, more interaction between the individual students and the teacher leading to greater confidence on the part of the former, and, finally, better classroom discussions (p. 120).

Diaries and journals used in university level courses often involve the students' writing entries throughout a semester-long course (for example, Absalom \& de Saint Léger, 2011, Huang, 2005). However, occasionally the requirement is reduced to a smaller number of times such as five over the course of fifteen weeks (Connor-Greene, 2000) in order to reduce the student workload. Many reports on diaries and journals in the literature involve the traditional paper and pen method of writing, but there is increasing use of such new technologies as wikis and blogs for doing them (for example, Absalom \& de Saint Léger, 2011).

\section{B. Student Reactions to Learning Diaries and Journals}

Student reactions to using diaries and journals in class are mentioned in passing in many papers but few studies appear to have focused on this aspect of reflective writing. Absalom \& De Saint Léger (2011) is one which does focus on learners' perceptions of using diaries and blogs to learn foreign languages at the university level. In their study, they examine student perceptions of the aims of using diaries and reflective blogs along with their satisfaction in writing them as part of their courses. The authors found that all of the students doing a blog felt that the activity was useful for their learning, while $87 \%$ of the students doing a traditional paper and pen diary felt this way. The most common explanations provided by the first group were related to being able to practice writing, becoming better organized through regular work, deepening their understanding of texts, increasing their confidence, receiving feedback from the professor and developing research skill. The reasons mentioned by the diary group coincided to some extent; the explanations included the chance to practice writing on a regular basis and the ability to become better organized by working on a regular basis, both of which were mentioned by the blog students, along with the opportunity to express feelings and reflections, the possibility to communicate with the professor, awareness of how they study, and development of linguistic skills (p. 201). Only $13 \%$ of the diary students claimed the activity was "a waste of time," the reasons being that it did nof help them develop their skills, the feedback was "poor" because the mistakes were not corrected by the professor and, most commonly (four students), it was "tedious and repetitive" (p. 204).

Mills (2008) picks up on this notion of negative attitudes on the part of students to journal writing in an article which proposes ideas to make diary and journal writing more amenable to the different temperaments in Keirsey's Temperament Model (1998, in Mills 2008). She refers to comments from four other papers which mention the downside of student attitudes towards this kind of activities. For example, Komara (2006) and Hearn (2005) are reported to have indicated that students "generally felt that journaling was not necessary for them to think critically or reflectively" (Mills, 2008, no page). ${ }^{1}$ Cisero (2006) is said to have "suggested" that "a strong negative attitude by students toward reflective journaling may often be present at the college level" (Mills, 2008, no page). In fact, the start to the title of Mills' paper is based on a student comment about the journal activity reported by this same author: "It's just a nuisance." Another two comments reported at the same time in Cisero and mentioned in Mills were that journaling was "busy work," and "tedious and unnecessary" (Cisero, 2006, p. 233). Finally, Mills reports that Connor-Greene (2000) claims that "A core group of students always seem to resist keeping reflective journals because they perceive it as simply busy work and, therefore, of no value" (Mills, 2008, no page). ${ }^{2}$ While these negative perceptions should not be ignored, it must be stressed that they benefit the interesting and valuable case made by Mills for variation in types of diary and journal exercises to bring them in line with Keirsey's different temperaments.

At the same time, it must be highlighted that both Cisero and Connor-Greene take a more positive albeit realistic view of journaling than Mills would like readers to believe. While Cisero (2006) points out possible shortcomings to journal activities and journals in general, such as their possible limitations for helping above average or below average students, she remains optimistic about their use and students' attitudes towards them: "many of the teacher education students in my recent classes liked the journal assignment so much that they planned to use it in teaching their respective students" (p. 234). Although this finding is anecdotal, it provides an indication that the negative viewpoints mentioned by Mills are not representative of the entire student population. At the same time, Cisero only mentions the three students' negative comments reported above. In contrast to them she cites another two very positive student reactions (p. 233) and other general anecdotal responses from students over the years. Connor-Greene (2000) is also more positive about journaling than Mills would lead readers to believe. She too notes limitations in her study in that it is only quasi-experimental and some unknown variables may have affected the results (p. 46), but a mean of 2.02 and standard deviation of .96 are reported for students' recommending continuation of the journal activity in her course on personality theories, and the comments made by the students on the questionnaire revealed that the "journals were a successful stimulus to active learning" (p. 45). A table of representative responses includes such aspects as being "pushed" to do class readings, having to "spend more time on each theory," becoming more creative, and having the chance to apply what is learned (p. 45).

\footnotetext{
${ }^{1}$ I have been unable to access Komara (2006) and Hearn (2005).

${ }^{2}$ Neither of Mills' allegations appears in the body of Cisero (2006) or Connor-Greene (2000).
} 
As noted above, most studies on diaries and journals do not focus specifically on student perceptions. Instead, brief comments of some students' appreciation for doing them can be mentioned in passing, if at all (for example, Halbach, 2000, p. 87). The results of the study by Absalom \& De Saint Léger (2011) mentioned above are encouraging but more work needs to be done to confirm that students are, in fact, receptive to writing them as a part of their learning process and to determine more clearly any reasons for student dissatisfaction. The present study seeks to provide additional findings about student attitudes towards a similar activity with a view towards making adjustments with future groups of students involved in learning English as a foreign language. Although the nature of the log activity discussed here differs from the studies on longer diaries and journals reported above, some student responses seem to show similar trends as will be discussed in more detail below.

\section{PARTICIPANTS AND METHOD}

This study concerns two different groups of learners who used independent study logs in their classes. The first group (henceforth Group 1) were teacher trainees in their second year of a primary education degree at a local university. Their long-term need for English is mainly due to the fact that teachers in Spain are finding jobs more easily if they have a certain level of English. Their short-term interest relates to their need to demonstrate a B1 level of English on the Common European Framework of Reference for Languages (CEFR) (Language Policy Unit) before starting the following year of their university degree program if they want to be accepted into a track involving more English courses over the final two years of study. At the start of the semester-long course in which they were asked to complete the study logs, their levels ranged from A2 to B2 on the CEFR. There were 30 students in the group.

The second group of learners (henceforth Group 2) were translation students in their second semester of the first year of the university degree program in modern languages and translation at the same university. Their long-term need for English is crucial as they are planning to work directly with the language as translators or interpreters. Their short-term need for the language was immediate as they were expected to pass an internal exam in the department offering the degree at the end of the semester to prove that they had a B2 level of the language and, hence, qualify to take the final exam for two of their English language courses. At the start of the semester their levels ranged from A2 to C1 on the CFR, meaning that some of them would have difficulty reaching the level requirement for the May exam, while others would have few problems to do so. There were 26 students in this group.

The log activity was explained to the two groups in the same way on the first day of class when the course requirements were introduced. The students were asked to record on paper the date and time that they studied English, any activities they did to work with the language, and their reaction (see Appendix B for student samples). During that same class, the professor explained some general notions related to learning English outside the class, stressing the need for actual use of the language including practice with the four skills of listening, speaking, reading and writing, along with traditional study of the grammar, vocabulary and pronunciation of the language. The logs were collected every two weeks over the course of 8 weeks in order to provide feedback. In the case of Group 1, completion of the log was included as part of the homework mark in the course, which came to $5 \%$ of the final result. The small percentage assigned to the log did, nevertheless, favor some of the students who had had some difficulty in completing some exercises successfully. Students' work on the logs in Group 2 was considered as half of the participation mark for their course, also $5 \%$ of the final result, but it had little impact on the students' overall grade.

Upon completion of the courses, the students in each of the groups were asked to fill out a short questionnaire on the last day of class. Group 1 did it in Spanish, their native language, but Group 2 answered the same questions in English as their level in the language overall was higher. Both groups filled it out in the same week. The questionnaires for the groups had one closed question and another open question (see Appendix A). Because the opinions were obtained during the last day of class, the students who were absent that day were not able to participate. Still, the number of students present to fill in the questionnaires was high and probably higher than might have been the case had the students been asked to do it in their own time. In addition, the students answered the questions individually in class and, in this way, did not consult with anyone else in doing so. In this regard, the results can be expected to be more valid.

During the initial analysis of the responses for Groups 1 and 2 it was soon observed that the closed question was too general and therefore misleading. The second question, which asked the students to explain their response to the first one, is what brought to light the inappropriate wording of the closed question; nevertheless, the comments provided reveal numerous student reactions to the independent study log activity which are valuable for considering in this article. The comments were analyzed following a suggestion of McDonough \& McDonough (1997) for the study of diary information, another form of open writing; it involves "reading and re-reading the text to allow significant themes to become gradually foregrounded" (p. 125). In this case, the criteria were ideas that were repeated but always ignoring the students' original labels for the log activity. For example, if a student wrote, "I think that it was interesting because it made me work more on English at home more often and more than in the past,"3 then the word "interesting" was ignored. This comment was then assigned to the category of "external motivation/obligation." When the student comments revealed more than one idea, they were divided into several categories. The student comment "thanks to the $\log$, I worked more and I saw the aspects that I have to improve" was separated into two different parts corresponding to

${ }^{3}$ The comments for Group 1 have all been translated into English from Spanish by the author. 
the categories of "external motivation/obligation" for the first part and "self-awareness" for the second part. For this reason, the total numbers of comments and students in each group do not coincide.

\section{RESUlts AND DisCUSSION}

As indicated in Section III, the questionnaires were completed by the students on the last day of class, meaning that those people who were absent were not represented in the final results. Twenty-eight of the 30 students enrolled in Group 1 responded to the questions, while 24 of the 26 students in Group 2 did so. Table 1 below shows the results for the closed question for Group 1. Because the students could choose more than one option, the total number of responses (66) is larger than the number of students answering the question.

TABLE 1

RESULTS FOR QUESTION 1, GROUP 1

\begin{tabular}{|l|l|}
\hline Label & Number of responses \\
\hline Interesting & 23 \\
\hline Motivating & 12 \\
\hline Innovative & 20 \\
\hline Boring & 2 \\
\hline A waste of time & 1 \\
\hline Other ideas & 8 \\
\hline
\end{tabular}

The comments listed under the vague term "interesting" included a variety of different things, some of which were actually covered under the other labels. The students' affirmations highlighted such aspects as the innovative nature of the log, the fact that it served to make them work more on their English outside class, their ability to see that they were improving in the language, increased awareness of what they do, and the possibility of seeing their progress, etc. Under "motivation" they listed similar things so the question was determined to be too vague. The "other ideas" mentioned by the students were "necessary," "useful" ( 2 people), "helpful for organizing and distributing study time" (2 people), and "helpful for knowing if activities are productive or not." The specific explanations for these other comments, however, relate to the above labels. Again, for this reason, it was decided that the question was too general and that the responses should not be taken at face value. Instead, the answers to the second question are more revealing. Table 2 below shows the categories determined upon analyzing the statements listed for question 2 and the number of responses obtained for each of them (total of 70).

TABLE 2

NEW CATEGORIES AND RESPONSES, GROUP 1

\begin{tabular}{|l|l|}
\hline Category & Number of responses \\
\hline Innovative & 15 \\
\hline Motivating (internal) & 15 \\
\hline Motivating (external) & 12 \\
\hline Self-awareness & 15 \\
\hline Teacher feedback & 6 \\
\hline A way to improve specific aspects of English & 2 \\
\hline Constraining (negative) & 2 \\
\hline Miscellaneous unrelated comments & 3 \\
\hline
\end{tabular}

Two of the original categories from the first question, innovative and motivating, can still be seen in the results here. The rest of the responses relate to self-awareness, a way of obtaining teacher feedback, and a way to improve specific aspects of the English language. The two negative comments reflected in the first table above and three comments not related to the $\log$ activity itself were also obtained. The differing numbers for the labels "innovative" and "motivating" in the two tables can be explained by the fact that the students sometimes answered question one but did not always provide an explanation for their response in the second question. In other cases, they discussed other, sometimes unrelated aspects of the course, such as the fact that they had had to read a short novel adapted for students and that they had found the task innovative and stimulating. Finally, some students described the exercise as being motivating but used the label "interesting."

The fifteen explanations provided for stating that the logs had been an innovative exercise mainly mentioned that they had never had to do something similar, but six of the students specified that they had never been asked to do a log or diary for their English classes. The fifteen responses represent just over half the group, a result that suggests that the activity was not, in fact, so new to them. Nevertheless, like other groups, they did seem to require several weeks to adjust to the requirement of including a reaction to the activities done each day (Litzler, 2014, in press). In fact, one student commented on this aspect of the exercise: "I have never had to do a diary where I put my opinion." Positive student reactions to adding their opinions and having freedom in doing diaries and journals have been mentioned by Pavlovich, Collins \& Jones (2007, p. 17). This is an area that would be worth investigating in more detail in future work

The 27 responses related to motivation can be divided into internal motivation and external motivation. The fifteen comments assigned to the former relate to intrinsic motivation in that they relate to studying "for the pleasure of learning, for the satisfaction of achievement, or to experience stimulation" (Benson, 2011, p. 84). Eight of these 
responses can be directly linked to the notion of satisfaction over achievement, as in "at the end of the week, you receive the big surprise of all the activities that you have done over the week." Two more comments are more general indications of improved levels of English and can, thus, be interpreted in a looser sense to relate to satisfaction over progress made, as in "it has helped me in learning the English language." Another four comments focus directly on the idea of stimulation, for example, "it was more pleasant for me to have a diary with a lot of activities than one that was empty," or "You can encourage yourself to do better than the week before." A final comment relates to the aspect of pleasure of learning in that the student highlights that she was able to select the activities done outside class. Data are not available for these students, but in future studies it would be interesting to examine the possibility of whether completing this type of logs for an English class does, in fact, lead to higher levels of proficiency thanks to the feelings of satisfaction and stimulation that they seem to encourage in some students. At this point it can be affirmed that 23 of the 29 students enrolled in the course received a passing grade or higher. At the same time, a number of students personally expressed their appreciation to the professor for the log activity at the end of the semester.

The twelve responses grouped under the label "external motivation" relate to extrinsic motivation in that they reflect reasons other than those mentioned above including rewards or pressure (Benson, 2011, p. 84). In fact, eight of the responses make specific mention of the "obligation" to study English while doing the log activity for class. Another three responses refer to studying more but in a way that appears to be more externally motivated than internally, as in "it made me work more on English at home." Four of these twelve comments specifically refer to daily work with English thanks to the log, for example, "it is a good methodology for the professor as well as the student as it requires you to look at the subject on a daily basis, not just the last day." Finally, a last comment relates to doing the log in order to improve a student's mark: "it isn't a waste of time as long as the log is counted in the final mark, in other words, it helps us on the final mark." While it would be preferable for these students to feel more motivated from within, it may still be beneficial for them to feel an obligation to work more with English for the course. Again, further, more extensive research could shed light on whether this feeling related to the logs activity is actually productive and whether it is linked to increased proficiency. Logs could also be used to determine whether motivation changes over time, a line of future work in this area, as indicated by Dörnyei \& Ushioda (2012, p. 406). In any case, it is worthy of note that so many responses related to motivation were obtained. More work on logs and motivation needs to be done.

The next category of comments is "self-awareness," which obtained fifteen responses. Nine of these student statements relate to increased understanding of what they do to learn English and the areas in which they need to work more. A major theme that stands out is "improvement," including "what I need to improve," "what I do to improve," and "seeing improvement." The difference compared to the category of internal motivation above is that these students mention the idea of "realizing" what they do, while the above comments relate more to an emotional level of satisfaction and feeling stimulated. For example, one student whose comment was assigned to the category of selfawareness stated: "when I reread it [the $\log$ ], I realized if I had worked enough and if I needed to work more on certain aspects, etc." Another theme that arises among these comments is "time" devoted to studying different aspects of English. Three students mention comments related to the possibility of needing more time after reviewing their logs, as for example, "in my opinion, it is a way to see if you are devoting enough time to English." A last student of these nine mentioned that the log helped her to realize what her mistakes in written English were. The other six affirmations in this category of self-awareness relate to increased ability to organize study time and activities for the course. Generally, they are generic comments about the log's helping them to organize themselves, but in one case the student indicates that by "reading a book, watching a film, or doing an activity that you like you can learn more than studying grammar rules alone." It is highly worthwhile for students to become aware of how they learn and what they need to do more in order to improve in English. It is also of interest for them to better organize their time. In this sense, the log activity appears to be a valuable activity because of these unexpected benefits that go beyond the original goal of learner training for language learning. More studies focusing on students' increased self-awareness through using study logs could determine if this sort of activity is more beneficial at certain levels of proficiency.

The last category of comments relates to the students' opportunity to receive teacher feedback, which was related to the professor's original intention of assigning the logs in class. Only six of the 29 students pointed out this aspect of the logs, a very low number. Five of these six comments mention the idea of the professor's "guiding," "advising" or providing "feedback" to the student. These few students managed to capture the essence of the activity. In fact, they were some of the most enthusiastic responses to the logs, as seen in the student comment: "I would say that it is the feedback that really helps; the log is a magnificent idea to be able to give all the students on-going and specific feedback." The sixth statement focuses on the idea that the professor can obtain information from the students and, based on the findings, modify the course itself, something which did, in fact, occur on a number of occasions throughout the semester. It is surprising to see that so few students mentioned the aspect of teacher feedback in doing the log. Nevertheless, the other positive results and reactions mentioned above also make work with logs worth pursuing more.

Finally, two short general comments were about the log's having helped the students to do activities in English and its having helped them to write in English. Another two comments were negative about doing the log activity. They referred to the "tedious" task of having to pay attention to how long it took to do homework, not being sure of what to include in the log, and having to think back to what had been done if the log was not filled in right away. This small 
number of negative responses is highly encouraging, especially considering the negative reactions reported elsewhere and described in section II.b. above.

Overall, this group can be said to have been highly receptive to the log activity. These results differ, however, from those obtained for Group 2. Table 3 below shows the results for question one, the closed question, for this second group.

TABLE 3

RESULTS FOR QUESTION 1, GROUP 2

\begin{tabular}{|l|l|}
\hline Label & Number of responses \\
\hline Interesting & 13 \\
\hline Motivating & 6 \\
\hline Unusual & 12 \\
\hline Boring & 9 \\
\hline A waste of time & 1 \\
\hline Other ideas & 2 \\
\hline
\end{tabular}

Once again, the explanations provided by this group of students for question two for the labels "interesting" and "motivating" included a variety of different ideas that overlap, as was the case for Group 1. For this reason, the comments were sorted into categories, as with the first group, without considering the original labels in order to determine any patterns. The other ideas listed as "a good idea" and "not useful" were also included in the new categories. Nevertheless, it is already clear from the above table that Group 2 was less positive about the log activity. Table 4 shows the results for this group for the second question after analyzing 60 student comments.

TABLE 4

NEW CATEGORIES AND RESPONSES, GROUP 2

\begin{tabular}{|l|l|}
\hline Category & Number of responses \\
\hline Unusual/Innovative & 8 \\
\hline Motivating (internal) & 8 \\
\hline Motivating (external) & 7 \\
\hline Self-awareness & 11 \\
\hline Teacher feedback & 3 \\
\hline General comments (positive) & 4 \\
\hline A way to improve specific aspects of English & 3 \\
\hline Constraining (negative) & 16 \\
\hline
\end{tabular}

As in Group 1, the two original categories of unusual and motivating from question 1 have been retained during the analysis of the student comments. Most of the other labels coincide with those determined in examining the information for Group 1. The only new category is for general comments of a positive nature. Overall, all of the positive labels for this group obtained lower numbers than in the first group. In contrast, there is a substantially higher number of negative comments for this group. In fact, the increase in negative comments compared to the answers for question 1 is related to the fact that some of the explanations for the label "unusual" involved complaints, rather than praise for the activity.

As can be expected, the comments that were kept for the category of "unusual" involved mentions of the students' never having done this type of exercise before. One student affirmed "when I see it, I think 'I've listened to music, I've done something related with English." Like Group 1, they needed some time to adjust to doing the exercise, suggesting that it was, in fact, something new for them, so more responses indicating that the activity had been unusual would have been expected. The word "unusual" in the questionnaire was probably misleading and possibly a factor responsible for the low number of responses here.

In terms of motivation, the fifteen comments found were far less enthusiastic than those for Group 1. Few students have the positive emotional response to the log in this case. Instead blander comments such as "I think it is a good idea to see your progress" are observed. This is one of eight internal motivation comments related to seeing achievement -as opposed to feeling satisfaction over their achievement. The fact that the comments indicate that the students saw their achievement but did not indicate satisfaction over it suggests once again that these students were less enthusiastic about their logs. It must be recalled, nevertheless, that this group of students answered the questions in English and, despite their relatively higher level of the language compared to Group 1, may still have had some difficulty or discomfort in expressing themselves in the foreign language. It might be interesting to do future questionnaires of this sort in their native language to eliminate this possible variable. The two other comments assigned to the category of internal motivation are linked to stimulation to work and again are less enthusiastic than those found for Group 1, as in "it makes me study more English." In fact, a few times it was difficult to determine whether the comments were really internal as opposed to external motivation. The aspect of external motivation mentioned or implied by practically all of the students in this category was the obligation to work more on English outside class (6 students). It is interesting to note, however, that two of the comments involved negative connotations, as in "had to" and "I have forced myself." Again, some of these comments may have been influenced by the fact that the students answered the questions in the foreign language. Finally, the last student mentioned having to be motivated because of the need to pass the level test mentioned in Section III above. The level test, which was to be taken at the end of the semester, is generally a source of considerable stress for students in this course. 
The comments under the category "self-awareness," like the comments in Group 1, mainly mention the notion of the students' becoming aware of what they need to "improve." One student differentiates between "learning" and "a waste of time" indicating that by reviewing the log he was able to have the chance to see what works best. Another affirms that the log helps to see "what we deserve in the final mark of the subject" in addition to becoming aware of what is done on a daily basis. As in the above categories, the comments are less enthusiastic, again possibly due to the language of the questionnaire. The lower number of comments under this label compared to the number for Group 1 may be related to the fact that some students in this group felt they knew how to learn English already and did not need help, as will be seen below.

The three comments about teacher feedback through the log activity were fairly general as in the other categories. While two students stress the importance of the professor's feedback, the other indicates that the information obtained through the logs can serve to help the professor to modify the day-to-day functioning of the class "and if he/she has to do more exercises about any of the skills." Once again, as in Group 1, it appears that the group overall missed the original idea for assigning the logs. They did not seem to be aware that the activity was designed to help provide them with suggestions for how to improve their level.

The four general comments included such ideas as "a good idea" or "it's very useful," so they merely reflect students' receptiveness to the exercise. The comments about the log as a way of improving specific aspects of English refer to the skills of listening and writing in one case and vocabulary and grammar in two others. The connection between the skills and the log is not clear due to the short and vague comments of the students, as in "it helps you to learn vocabulary and grammar." Further questioning of the students might have revealed that this was actually a case of self-awareness or motivation through observation that the student needed more work in these areas.

Finally, the comments that stress constraints can be divided into several categories. Three students mention their being busy and not having time to do the log. In the semester that they did the log, they have an especially heavy workload in all of their courses and students in this semester tend to feel quite stressed. Seven students seem to show resistance to the idea of writing what they do down on paper, as reflected in a comment by a student who said that it "is like returning to primary school." Others simply mention that they are not used to writing everything done, an idea reflected in Group 1 too. One person points out that the information can be invented, again mentioned by one of the students in the other group. Four students indicate that they already know how to study a foreign language or that it is part of their routine already. In fact, one of them affirms that "we don't need a paper to know that." Some of the students in this group had a B2 or C1 level in the language, so it is natural that they are used to studying the language and have probably established their own routines for learning. This would explain some if not all of their reticence at having to report what they do to practice the language. Another student completely missed the idea of the log as revealed through the comment "I think not just with writing down what we have done, we can get a better level." This person clearly did not realize that the idea was to obtain suggestions from the professor on how to improve in the foreign language. Nevertheless, despite the larger number of negative reactions to the log activity compared to Group 1, it should be noted that four of the students who responded with negative comments qualified them with other indications that they understood the benefit or reason for doing them, as in "I think that the idea is good but write every day what you had done is boring."

The two groups clearly show differing overall perceptions to doing the log activity as part of their English classes. As seen above, Group 1 was enthusiastic about the experience, while Group 2 is less receptive overall to it and had more negative responses. The differences in the two groups appear to be related to various factors. The language used for the questionnaire may have had a partial impact on the expression of the Group 2 students, at least in some of the cases. Nevertheless, a number of them did, in fact, have a B2 or C1 level in English so they could be expected to express themselves with a fair degree of precision in the language. A second factor to explain the variation between the two groups is their level in the target language. Group 1 generally had a lower level compared to Group 2. For this reason, they may have been more open to the logs. Generally, students in this course tend to have the feeling that they have never succeeded in English and they feel lost as to how to proceed.

It is clear that more time must be spent on the first day of class to discuss the reasons for doing the log activity. The students in both groups clearly missed the point of the exercise as revealed by the low number of responses reflecting the opportunity to obtain teacher feedback. At the same time, it would also be worthwhile to consider making the log activity voluntary. This would enable students who feel comfortable already with their language learning ability to opt out of doing it. More work is needed to determine whether this log activity might be more useful for lower level students or to see if it needs to be modified for higher level learners.

\section{CONCLUSION}

This article has explained the reactions of two groups of students to using independent study logs as part of their English courses at the university level based on a questionnaire. The first group, teacher trainees with a level of English around A2-B2, was overwhelmingly positive about the experience, expressing comments related to the innovative nature of the logs and to intrinsic and extrinsic motivation along with self-awareness as a result of doing them. A small number of these students mentioned the possibility of obtaining teacher feedback on how to study, meaning that the majority of the group missed the original point. The second group, translator trainees with levels ranging from A2-C1, 
were less receptive to the activity and more neutral in their comments even when they were positive about the experience. Nevertheless, the comments were found to be related to the same areas as in the first group: the unusualness of the logs, motivation, self-awareness, and teacher feedback, among others.

Additional work with logs and students' perceptions about them is needed to confirm these results. The questions and language of the questionnaire should be adapted in future studies. At the same time, the high number of responses related to motivation and self-awareness suggest that more work should be done in these areas. Both concepts are beneficial to learners and it would be valuable to determine if these characteristics can be developed more through the use of logs.

\section{APPENDIX A. SURVEY FOR GROUPS 1 AND 2}

Group 1 was issued the questionnaire in Spanish. Group 2 did it in English.

Answer the following questions

1. I found doing the log (you can select more than one answer):
a. Motivating
b. Interesting
c. Unusual (Innovative - Group 1)
d. Boring
e. A waste of time
f. Another idea (write the word)

2. Explain all of your ideas in as much detail as possible.

\section{APPENDiX B. SAMPLE Log ENTRIES}

Student 1

\begin{tabular}{|l|l|l|l|}
\hline February 6, 2013 & Page 136 and 137 (4A) Grammar & 15 min. & Entertaining activity \\
\hline February 12, 2013 & Read book "Strangers on a Train" & 2 hours & $\begin{array}{l}\text { Boring activity because I had to look at the } \\
\text { translator. I didn't understand the words often. }\end{array}$ \\
\hline February 12, 2013 & $\begin{array}{l}\text { Photocopies and phonetics and } \\
\text { pronunciation }\end{array}$ & $15 \mathrm{~min}$ & $\begin{array}{l}\text { Fun activity because I like this theme, although I can } \\
\text { [it can be?] complicated. I helped the page } \\
\text { www.wordreference.com/es/. }\end{array}$ \\
\hline
\end{tabular}

\section{Student 2}

\section{$5 / 3 / 2013$}

I watched The Client List Serie. It was the last chapter of the first season, and I'm really intrigued for know what will happened. ( \pm 1 hour) At the University, in English Subject, we studied the present perfect simple and continuous and at finished these class I was very confused, and for to do easier to learn that, first, the teacher explained the present perfect and past simple grammar. (1 hour and 30 minutes). $6 / 3 / 2013$

That day I went to my English academy and we studied the vocabulary, nouns and verbs and -ed and -ing adjectives, then we practiced speaking in one hand in group and in the other hand in pairs and realiced [did] listening and discriminated [distinguished] the / $\mathrm{r} /$ and /j/ sounds. (1 hour and 15 minutes).

$7 / 3 / 2013$

I readed my novel, Love Actually, two chapters (30-45 minutes), and realiced my university homework of English ( \pm 45 minutes). It's a little time but I had made a part of that exercises.

\section{Student 3 (translated from Spanish)}

\section{$7 / 3 / 2013$}

Viewing of the first part of the NBA match Indiana Pacers-Boston Celtics. Since starting with sports broadcasts I have noticed a big improvement in my listening, even though I think that I have hit a rut or the process is much slower than before. I need a lot of vocabulary to understand it all. Time: 1 hour.

Did the homework, not too many problems doing it with the theory from the book. Time: 25 min. Total time today: 1 hour 25 min.

$8 / 3 / 2013$

I went to the website for the textbook and did the exercises there for vocabulary and grammar for unit 4 . I made some mistakes but in general pretty good. Time: $45 \mathrm{~min}$.

$12 / 3 / 2013$

I saw the first part of the Philadelphia 76ers and Brooklyn Nets match without anything new. I can say the same as on 7/3/2013. I also listened to music in English but I do this almost every day, but today I realized that I understood a lot of parts of the songs. I don't know if it is because the singers were German that I understood so much. Time: 1 hour $10 \mathrm{~min}$.

\section{REFERENCES}

[1] Absalom M. and D. de Saint Léger. (2011). Reflecting on reflection: Learner perceptions of diaries and blogs in terciary language study. Arts \& Humanities in Higher Education 10.2, 189-211. doi: 10.1177/1474022210389141 (accessed $13 / 03 / 2014$ ). 
[2] Bailey K. and R. Ochsner. (1983). A methodological review of the diary studies: Windmill tilting or social science? In K. Bailey, M. Long and S. Peck (eds.), Second language acquisition studies. Rowley, MA: Newbury House, 188-198.

[3] Benson, P. (2011). Teaching and researching autonomy (2nd edn.). Harlow, England: Longman.

[4] Blaschke, L. and J. Brindley. (2010). Establishing a foundational framework for development of reflective thinking: Learning journals in the MDE. www.eden-online.org (accessed 17/03/2014).

[5] Cisero, C. (2006). Does reflective journal writing improve course performance? College Teaching 54.2, 231-236. http://wweb.b.ebscohost.com (accessed 17/03/2014).

[6] Connor-Greene, P. (2000). Making connections: Evaluating the effectiveness of journal writing in enhancing student learning. Teaching of Psychology 27.1, 44-46. http://web.a.ebscohost.com (accessed 17/03/2014).

[7] Dörnyei, Z. and E. Ushioda. (2012). Motivation. In S. Gass and A. Mackey (eds.), The Routledge handbook of second language acquisition. New York: Routledge, 396-409.

[8] Halbach, A. (2000). Finding out about students' learning strategies by looking at their diaries: A case study. System 28, 85-96. www.elsevier.com/locate/system (accessed 27/01/2014).

[9] Hearn, K. (2005). Artifacts of thought: Evidence of meta cognition in twelfth-grade student reflective journal writing, Ph.D. dissertation. Wayne State University, Detroit, Michigan.

[10] Huang, J. (2005). A diary study of difficulties and constraints in EFL learning. System 33, 609-621. www.elsevier.com/locate/system (accessed 27/01/2014). doi: 10.1016/j.system.2005.04.001.

[11] Keirsey, D. (1998). Please understand me II. Delmar, California: Prometheus Nemesis Books.

[12] Komara, C. (2006). Reflective journaling: Can students be taught to be reflective in their writing? Ph.D. dissertation, University of Kansas.

[13] Language Policy Unit, Common European framework of reference of languages: Learning, teaching, assessment. Strasbourg: Council of Europe. www.coe.int/lang-CEFR (accessed 15/02/2014).

[14] Litzler, M. F. (2014, in press). Independent study logs: Guiding and encouraging students in the process of language learning. Journal of Language Teaching and Research, 5.

[15] McDonough, J. and S. McDonough. (1997). Research methods for English language teachers. London: Arnold.

[16] Mills, R. (2008). It's just a nuisance: Improving college student reflective journal writing. College Student Journal 42.2, 684691.

[17] Moon, J. (2010). Learning journals and logs. Centre for Teaching and Learning, UCD Dublin http://www.deakin.edu.au/itl/assets/resources/pd/tl-modules/teaching-approach/group-assignments/learning-journals.pdf (accessed 03/04/2014)

[18] Nunan, D. (1992). Research methods in Language Learning. Cambridge: Cambridge University Press.

[19] Pavlovich, K., E. Collins and G. Jones 2007. Developing students' skills in reflective practice: Design and assessment. Journal of Management Education. doi: 10.1177/1052562907307640 (accessed 17/03/2014).

Mary Frances Litzler holds a Ph.D. in English from the University of Las Palmas de Gran Canaria (Spain) since 2011 and an M.A. in Applied Linguistics from the University of Southern California since 1987. In recent years she has been teaching English at the British Council Foundation and English language, linguistics and translation at the University of Alcala in central Spain. Her research interests and publications relate to learner autonomy, student attitudes towards classroom methods, testing, new technologies and teacher training. 